\title{
Autorregulación y la publicidad sexista: Oportunidad de mejora para el CONAR(*)
}

\section{Self-regulation and sexist advertising: Opportunity for improvement for CONAR}

\author{
Alex Sosa $\left({ }^{* *}\right)\left({ }^{* *}\right)$ \\ Universidad del Pacífico
}

\begin{abstract}
Resumen: En el presente artículo, el autor desarrolla la problemática de la publicidad sexista y plantea la autorregulación como una alternativa para sancionarla. En esa línea, introduce al CONAR como una institución encargada de la autorregulación dentro de la publicidad, y destaca la emisión de un criterio objetivo para la evaluación y eventual sanción de la publicidad sexista, esto en el marco de la vigencia de su Código de Ética Publicitaria del 2007, pero luego de una serie de modificaciones al marco regulatorio, el autor crítica su falta de aplicación, y culmina afirmando las ventajas de una autorregulación publicitaria, representada a través del CONAR.
\end{abstract}

Palabras clave: Publicidad sexista - Autorregulación - Código de Ética Publicitaria - CONAR - Principio de Adecuación Social.

\begin{abstract}
In this article, the author develops the problem of sexist advertising and he sets out self-regulation as an alternative to sanction it. Along these lines, he introduces CONAR as an institution responsible for self-regulation within advertising, and he highlights the issuance of an objective criterion for evaluation and eventual sanction of sexist advertising, this within the framework of the validity of its Advertising Code of Ethics 2007, but after a series of modifications to regulatory framework, the author criticizes its lack of application, and he culminates
\end{abstract}

$\left(^{*}\right) \quad$ Nota del Editor: Este artículo fue recibido el 11 de mayo del 2018 y su publicación fue aprobada el 20 de junio del mismo año.

${ }^{* *}$ Jefe del Área de Competencia y Relaciones de Consumo de AMÉRICA MOVIL PERÚ (CLARO). Magíster en Derecho de la Propiedad Intelectual y de la Competencia por la Pontificia Universidad Católica del Perú. Abogado Summa Cum Laude por la Universidad de Lima. Profesor de cursos de competencia desleal en la PUCP, Universidad del Pacífico y USMP. EI autor fue Secretario Técnico del CONAR durante el periodo 2009 - 2015. Correo electrónico: alex.sosa@claro.com.pe

$\left({ }^{\star * \star}\right)$ El autor agradece a Malena Cárdenas Tello, Betty Cordero y Jazmín Martínez por sus comentarios. 
affirming the advantages of an advertising self-regulation, represented through CONAR.

Key words: Sexist Advertising - Self-regulation - Advertising Code of Ethics - CONAR - Principle of Social Adequacy.

Sumario: 1. Breve historia de la regulación de la publicidad sexista en el Perú_2. ¿Qué ha hecho el CONAR frente a la publicidad sexista?_3. ¿Qué debería hacer CONAR?_4. Referencias Bibliográficas

\section{Breve historia de la regulación de la publicidad sexista en el Perú}

Desde la década de 1990 hasta la actualidad, el Instituto Nacional de Defensa de la Competencia y de la Protección de la Propiedad Intelectual (En adelante, "INDECOPI") ha pasado por varios momentos controvertidos acerca de su función o responsabilidad frente a la publicidad indecente, antisocial o sexista que difunden algunos anunciantes, en los que siempre se le ha demandado tener mano dura con los anuncios que no son de nuestro agrado por su mal gusto, falta de decencia o cuando consideramos que podría reforzar algún aspecto negativo de la sociedad como el machismo o sexismo. Y ahora, con las redes sociales, esas exigencias se hacen cada vez más frecuentes.

Varios especialistas han escrito sobre un periodo bastante complejo en el que el INDECOPI, en aplicación de lo que disponía el derogado Decreto Legislativo 691, sancionaba todo tipo de anuncio que podía enaltecer conductas antisociales, como entre otros, la publicidad de mal gusto, la sexista y la discriminatoria. En ese entonces, se criticaba el hecho de que no existían criterios objetivos para resolver ese tipo de casos, pues la aplicación de la norma generaba inseguridad jurídica en el mercado, toda vez que el criterio de sanción terminaba dependiendo de los funcionarios de turno que conocían del caso, bajo la percepción del buen o mal gusto o concepción de la ética y la moral en la publicidad que podían tener.

Todo lo anterior sin descontar que al final del día se utilizaban recursos públicos del Estado para imponer a la sociedad parámetros morales o de decencia de los funcionarios que aplicaban la norma, cuando ellos mismos podían sancionar esos anuncios con el rechazo a los productos promocionados o simplemente, cambiando de canal.

En el 2008, la Ley de Represión de la Competencia Desleal (en adelante, "LRCD"), a través del principio de adecuación social, reformuló lo que se venía sancionando y dispuso que solo serían ilícitos los anuncios que induzcan la realización de conductas ilegales o discriminatorias, asegurando de este modo que no se sancione más la publicidad que estimule, enaltezca o exalte conductas antisociales por lo discrecional que terminaba resultando esta regulación. Ya luego en el 2010, un truculento artículo 13 del Código de Protección y Defensa del Consumidor parece introducir de contrabando nuevamente la prohibición de difusión de anuncios antisociales dentro del principio de adecuación social, pero esa ya es una historia para otra investigación ${ }^{(1)}$.

Sin embargo, más allá de esta interesante discusión, lo cierto es que quizás no nos hemos

(1) Sobre los conflictos constantes que existen entre la regulación de la publicidad comercial y cuando esta afecta la libertad de expresión, Posner comenta lo siguiente: "las grandes dificultades implicadas en la cuantificación de los costos y beneficios de la libertad de expresión en un método caso por caso han generado sugerencias para el reconocimiento de una jerarquía de categorías del discurso donde, por ejemplo, el discurso político y el científico recibieran la máxima protección bajo el supuesto de que son los más valiosos desde un punto de vista social o de que (en el caso del discurso político) es más fundamental para los intereses que animaron a los autores y ratificadores de la Primera Enmienda. Con este enfoque, la publicidad comercial recibiría menos protección, junto con el arte y el entretenimiento, incluida la pornografía, mientras que las amenazas y las peticiones delictivas no recibirían ninguna protección". Richard Posner, El análisis económico del Derecho (México: Fondo de Cultura Económica, 1998), 1053. 
Alex Sosa

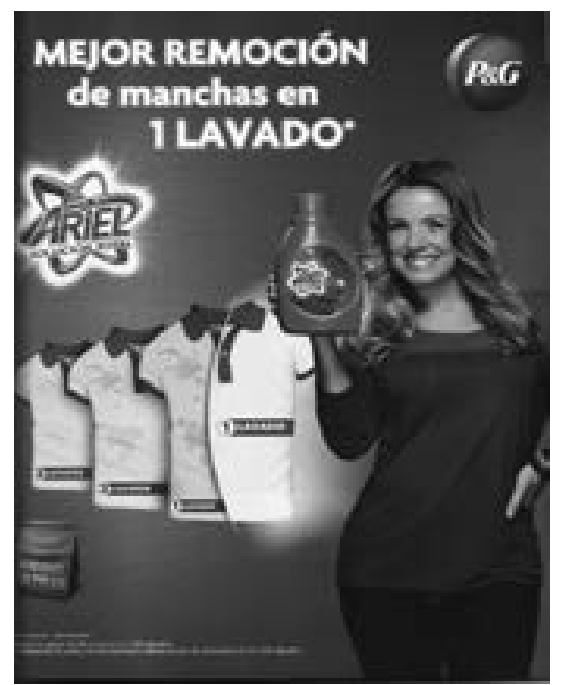

Fuente: pinterest.es

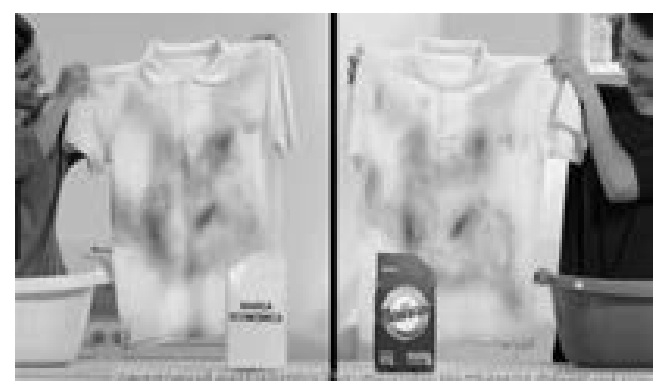

Fuente: youtube.com

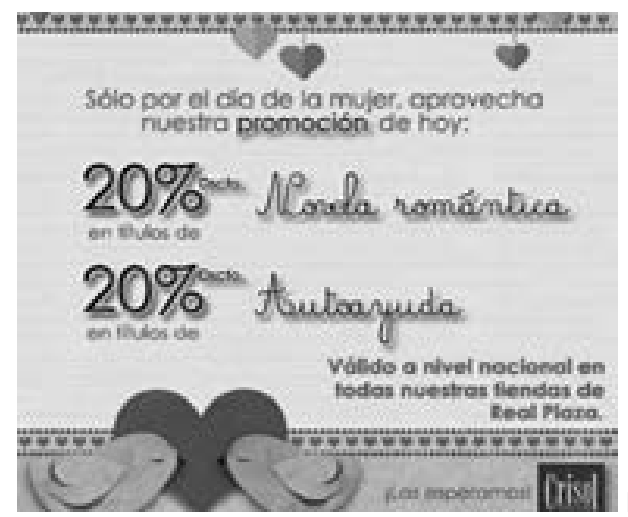

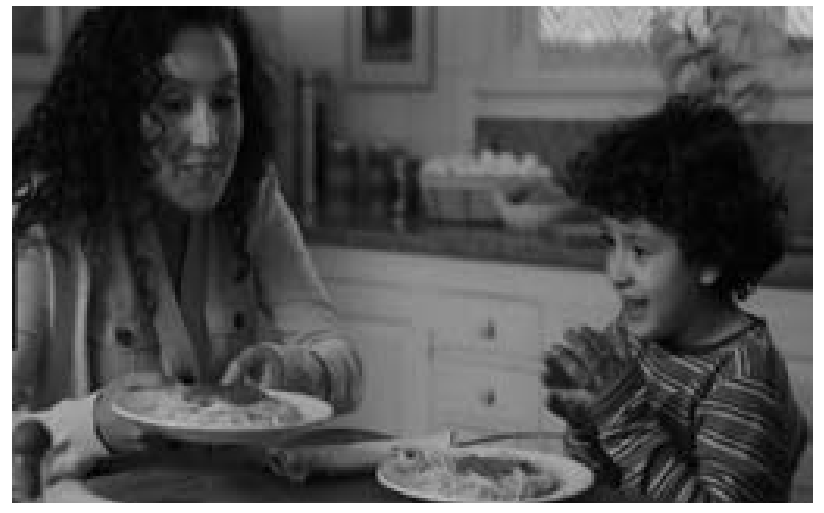

Fuente: imagen extraída de youtube.com

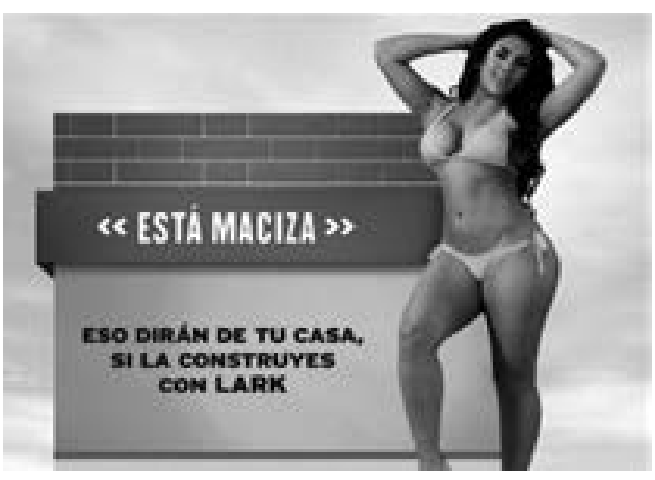

Fuente: peru21.pe

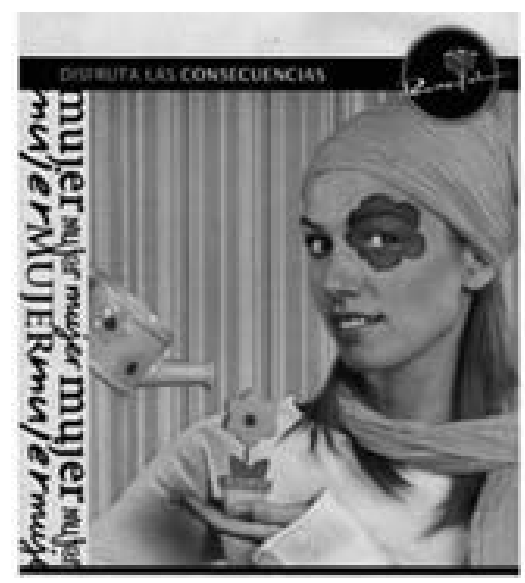

Fuente: peru21.pe 


\section{Autorregulación y la publicidad sexista: Oportunidad de mejora para el CONAR Self-regulation and sexist advertising: Opportunity for improvement for CONAR}

detenido a analizar si realmente era necesario o no fiscalizar los anuncios que enaltezcan o refuercen conductas antisociales, y en este punto quiero concentrarme respecto a la publicidad sexista.

Ahora bien, con esto no pretendo concluir que la publicidad sea la culpable de lo podrida e indiferente que resulta nuestra sociedad frente a los derechos de las mujeres, pero sí creo que podría estar aportando su granito de arena ${ }^{(2)}$. Y es que si bien estoy completamente convencido de que la publicidad no nos obliga a comprar o adquirir un producto o servicio (por lo cual no debería prohibirse ni establecer restricciones a la publicidad de cigarrillos, comida chatarra, bebidas alcohólicas etc. etc. Ello toda vez que su función solo es persuasiva), lo que me genera serias dudas respecto a si la publicidad puede reforzar conductas negativas en la medida que es un "reflejo de nuestra sociedad", como dicen algunos ${ }^{(3)}$.

No pretendamos tapar el sol con un dedo. $\mathrm{Si}$ bien se han presentado ciertas mejoras en la publicidad, seguimos viendo muchos anuncios en los que se nos muestra a la mujer como ama de casa (vean los anuncios de fideos, detergentes, artículos del hogar, línea blanca, entre otros) o hacen uso de su cuerpo con la finalidad de generar la atención de sus receptores. ¿Recuerdan el anuncio de Ladrillos Lark usando a Vania Bludau?(4) $U$ otras tan

(2) "Once society has made its mind up about a particular product, over many years and often centuries, advertising is not nearly a sufficiently powerful force to make people change their minds. Advertising can most definitely sell brands, but its role in social engineering is minimal, if it exist at all. (It is true that advertising has helped discourage drunken driving. But, as with smoking, the advertising was backed by strong legislation, police activity, breathalysers, and relentless press publicity. Advertising alone would never have done the trick.)" Winston Fletcher, Advertising. A Very Short Introduction (New York: Oxford University Press, 2010), 121.

(3) Por su parte, Lema Devesa sostiene que: “(...) no puede exigirse a la publicidad que contribuya a establecer el principio de igualdad o equiparación entre los sexos. Se ha dicho que la publicidad se limita a reflejar los comportamientos que rigen en la sociedad. Pero que no es su misión, ni deber primordial, cambiar los valores sociales, sino que este cambio deben procurarlo los poderes públicos. En fin, incluso los publicitarios y publicitarias se defiende preguntando si sería degradante para la mujer mostrarla atractiva en el plano afectivo o sexual." Carlos Lema Devesa, Problemas Jurídicos de la Publicidad, (Madrid: Marcial Pons, Ediciones Jurídicas y Sociales, 2007), 338.

(4) Sobre el mismo problema en España García López señala lo siguiente: "Debido a la situación actual en España, donde la llamada violencia de género y el machismo recalcitrante inserto en nuestras comunidades más cercanas se sitúan diariamente en la agenda mediática, este tipo de proceso dispublicitador es especialmente relevante. Todo ello a pesar de que la distancia que parte de la oposición hombre-mujer no es muy representativa en la mayoría de anuncios. Al ser un tipo de discriminación emergente, la publicidad no suele dejar rastro de posibles desigualdades en este sentido. No hay que olvidar que existen en nuestro país numerosos intentos de concienciación por parte de diferentes estamentos sociales; la discriminación de género es un tipo de discriminación que está altamente controlada por ciertos observatorios dedicados a la erradicación de las desigualdades de la mujer con respecto al hombre. Podríamos decir que este tipo de desigualdad social, si la hay en publicidad, queda doblemente oculta en los relatos publicitarios.

$(\ldots)$

Otro ejemplo de este tipo de publicidad podría ser el anuncio de Cillit Bang. En la narración se muestra a un hombre, experto en limpieza, aunque sin mancharse. La protagonista de la ficción, harta de tener que fregar, necesita un producto potente que le haga su vida mucho más cómoda. La mujer, que no es experta en nada, requiere una solución. La mayoría de productos para el hogar se encaminan hacia un público femenino de clase media. Entre todos los bienes de consumo que forman parte del contexto hogareña, destacan los productos de limpieza. Y es obvio (aunque no debería considerarse habitual) que este tipo de útiles se aleje de las clases altas y se comunique directamente con la mediocridad de lo cotidiano de una mujer normal (es necesario apuntar de nuevo que la clase media española es el colectivo más habitual en el ámbito del consumo y de la publicidad).

Como se percibe en este anuncio, la mujer no es capaz de encontrar salida al problema; necesita del hombre para ello. Cuando el hombre le ofrece la salida a todos sus problemas vitales, la mujer explica de un modo sincero: “¡Pero qué más quiero!”. Una vez desmenuzado el relato parece evidente que la mujer dispublicitada es la presa de este tipo de anuncios publicitarios". Javier García López, Dispublicitados. Los efectos (ideológicos) de la publicidad, (Murcia: Universidad de Murcia, 2016 ), $239-242$. 
Alex Sosa

graves como los que terminaron transmitiendo que las mujeres solo leían novelas románticas y libros de autoayuda; o el que mostraba a la mujer con algo bastante parecido a un golpe en el ojo acompañado de la frase disfruta de las consecuencias.

Pero claro, para hablar de regular este tipo de publicidad debemos tener claro el impacto que podría generar dicha regulación en el mercado y para ello se debe de acreditar que la propuesta regulatoria sea idónea para perseguir el objetivo planteado, que sus beneficios sean mayores que los costos que pueda generar ${ }^{(5)}$, pero sobre todo, que ésta sea necesaria por no existir una alternativa menos costosa y es aquí donde quiero detenerme, pues considero que existen al menos dos alternativas que no se han explorado de manera exhaustiva y se encuentran estrechamente relacionadas: (i) el sistema de autorregulación y (ii) medidas de autocontrol tomadas por la propia empresa. Ello, toda vez que estoy convencido que la intervención del Estado en estos casos a través de prohibiciones o restricciones publicitarias sería completamente ineficaz ${ }^{(6)}$.
Por las limitaciones de extensión del presente artículo, me voy a concentrar en el tema de la autorregulación, no sin antes decir que un buen ejemplo de autocontrol empresarial es la propuesta publicitaria de los últimos años de Backus, que ha decidido no hacer uso de la sexualidad y el erotismo en la publicidad de todas sus marcas. Un excelente cambio de 180 grados, pues en la década de 1990 nos tenía acostumbrado a solo ver mujeres en bikinis en todos sus anuncios.

\section{2. ¿Qué ha hecho el CONAR frente a la publicidad sexista?}

La alternativa fiscalizadora de este tipo de anuncios que está desaprovechando desde hace buenos años la oportunidad para hacerse notar es la autorregulación, que en el Perú se

(5) Sobre la regulación estatal de la publicidad sexista, Rubi i Puig ha señalado que "(...) A falta de acreditación de tales juicios fácticos, deberán buscarse otros daños para fundamentar una restricción en las expresiones comerciales que utilicen el cuerpo de la mujer. Una posibilidad es entender que las prohibiciones de ciertas manifestaciones encuentran sus justificaciones en evitar que las mujeres tengan que manifestarse en un ambiente hostil, dominado por creencias y estereotipos que las reduzcan a objetos sexuales. Se puede defender que se restrinja la libertad de expresión de unos para posibilitar que otros hagan efectivos esa misma libertad: que no deban callarse lo que quieren para utilizar su tiempo y esfuerzo en defenderse y en contradiscursos.

La cuestión es, en efecto, otra y poco o nada tiene que ver con la regulación de las comunicaciones comerciales. En este sentido, sería posible concebir que los daños asociados al posible menoscabo de la dignidad de las mujeres, así como de otros grupos minoritarios, o de determinadas creencias religiosas e ideologías políticas mediante manifestaciones denigratorias y los problemas de acción colectiva vinculados a la existencia de una pluralidad de afectados y la falta de incentivos para perseguir las expresiones pudieran motivar, en su caso, regulaciones restrictivas. En cualquier caso, no se trata de una problemática exclusiva de la publicidad comercial.

Por ello, no existen razones normativas o positivas para llevar a cabo una distinción fundada en el hecho de que este tipo de manifestaciones aparezcan en un anuncio o en una obra artística o literaria. Su aparición en la publicidad no debería servir pues como argumento para relajar el grado de protección, salvo que distorsionen de forma efectiva y sustancial la competencia en el mercado". Antoni Rubi i Puig, Publicidad y Libertad de Expresión, (Pamplona: Editorial Aranzadi, 2008), 393-394.

(6) "Las prohibiciones a la publicidad gozan de atractivo político por todas las razones equivocadas. A las empresas establecidas y a sus lobistas les gusta las prohibiciones ya que las protege contra la competencia de los agentes del mercado nuevos y los forasteros. A los políticos les gustan las prohibiciones porque al parecer ofrecen una manera de atacar los problemas sociales sin tener que gastar el dinero recaudado de los impuestos. Mientras que a los activistas de la salud les agrada las prohibiciones porque conseguir una prohibición de la publicidad demuestra la capacidad de "hacer algo" sin hacer nada constructivo en la realidad. Por último, a todo tipo de personas les gusta todo tipo de prohibiciones de la publicidad -juguetes, alcohol, medicamentos, entre otros- debido a que piensan que las prohibiciones podrían ayudar, pero no ven cómo pueden hacer daño." John Calfee, Miedo a la persuasión. Una nueva perspectiva de la publicidad y sus reglas, (Lima: Themis, 2013), 132. 


\section{Autorregulación y la publicidad sexista: Oportunidad de mejora para el CONAR Self-regulation and sexist advertising: Opportunity for improvement for CONAR}

ve representada por el Consejo de Autorregulación y Ética Publicitaria (En adelante, "CONAR"), una entidad privada que sí puede auto proclamarse como defensora de la ética en la publicidad. De hecho, su código de conducta se denomina Código de Ética Publicitaria ${ }^{(7)}$.

Dicho Código si bien es bastante similar a la LRCD (porque tiene un deber de compatibilidad), contiene restricciones de contenido ético que tienen la finalidad de generar que la publicidad no pierda sus valores morales. Por ejemplo, el Código de Ética del 2007 (actualmente derogado), entre otras modalidades publicitarias, sancionaba la publicidad que hacía uso indebido y discriminatorio de la figura de la mujer, sobre todo cuando su imagen era utilizada únicamente como objeto de impacto para captar la atención del público(8).

De hecho, sobre la base de las restricciones contenidas en ese Código del 2007, el CONAR emitió, a través de sus resoluciones, un criterio objetivo bastante interesante para evaluar este tipo de publicidad, el cual señalaba que se podía hacer uso de la figura femenina o masculina en la publicidad siempre que su uso se encuentre directamente vinculada al producto publicitado y su presencia tenga un rol activo en el contexto del argumento publicitario.

Así, CONAR declaraba infundada una denuncia interpuesta contra un anuncio de ropa interior en el que se mostraba la imagen de una reconocida modelo internacional vistiendo lencería, pues, justamente, el uso de la modelo en ropa interior se encontraba estrechamente vinculado con el producto que el anunciante pretendía vender (resulta risible exigir que maniquíes modelen lencería ¿no?) $)^{(9)}$.

Imagen extraída del Expediente No 12-2012/CONAR

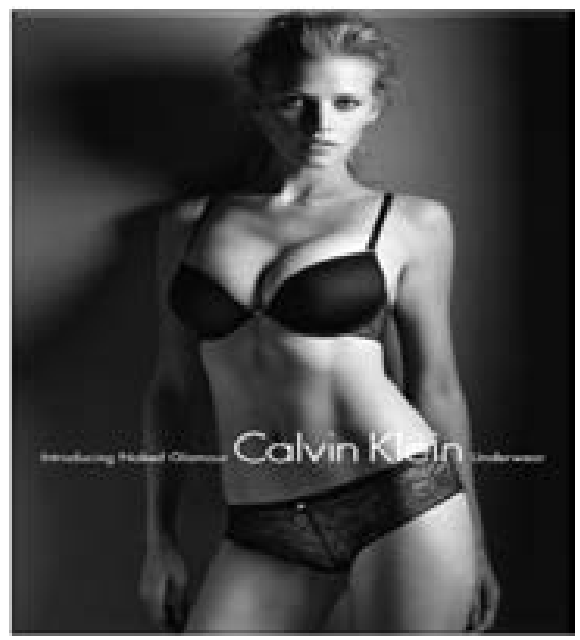

Fuente: wordpress.com

(7) Para los que no saben que es la autorregulación, lo podemos explicar de forma bien sencilla. En líneas generales, la autorregulación es un sistema de solución de controversias extrajudicial que nace del acuerdo voluntario de miembros de determinado sector que buscan autoimponerse códigos de conducta o deontológicos compatibles con la Ley que regula la materia y que cuentan con la estructura necesaria como para poder aplicar los referidos códigos, y a la vez cuentan con la capacidad de poder hacer cumplir sus disposiciones y sanciones. CONAR cumple con todos esos requisitos y existe en el Perú desde el año 1997 (pero su participación activa se empezó a notar desde el 2010).

Dicha entidad cuenta con la capacidad para hacer cumplir sus medidas (que por lo general consisten en ordenar el cese de la difusión del anuncio), toda vez que utiliza a la Sociedad Nacional de Radio y Televisión - SNRTV como herramienta para hacer cumplir sus disposiciones (la SNRT controla el 90\% de medios de comunicación en el país lo que garantiza el cumplimiento de las resoluciones de CONAR) y lo que es mejor, si bien tiene la obligación de contar con códigos de conducta que sean compatibles con la LRCD, pueden ser más exigentes o restrictivos para reprimir conductas no deseadas, como de hecho lo hace, pues históricamente, los códigos de ética del CONAR han reprimido de forma más severa el uso de la sexualidad en la publicidad y la publicidad indecente (a través del principio de decencia publicitaria).

(8) Código de Ética Publicitaria (2007).

Artículo 9.- Análisis de la sexualidad en la publicidad

El sexo y la sexualidad serán tratados con dignidad en los anuncios comerciales.

Podrán ser considerados indecentes los anuncios en función de:

a. La naturaleza gráfica o explícita de las representaciones o descripciones de órganos o actividades sexuales o excretoras. b. Si es que el material gira alrededor o repite insistentemente representaciones o descripciones de órganos o actividades sexuales o excretoras. 
Alex Sosa

Un año después, en aplicación del mismo criterio, CONAR sancionó a una reconocida marca de gaseosas que utilizó en un panel publicitario la figura de una mujer en bikini que mostraba su trasero untado de bloqueador acompañada de la frase: "tu amigo es más peligroso que el sol". Evidentemente, el uso de la figura femenina en bikini se encontraba completamente descontextualizada, pues no tenía vinculación alguna con el producto.

\section{Imagen de la Resolución No 2-2013-CONAR/CPE}
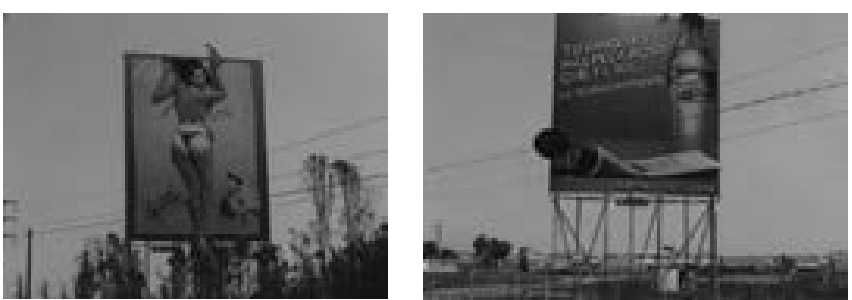

Sin embargo, en el año 2014, el criterio que parecía bastante objetivo para poder evaluar la publicidad sexista fue dejado sin efecto por el CONAR mediante Resolución No 2-2014-CONAR/ $J D$, toda vez que el anuncio denunciado se encontraba en una zona bastante gris, por decir lo menos. Tanto así que sobre la base del mencionado criterio podía sancionarse un anuncio que para los miembros de la Junta Directiva del CONAR no calificaría de ninguna forma como publicidad sexista:

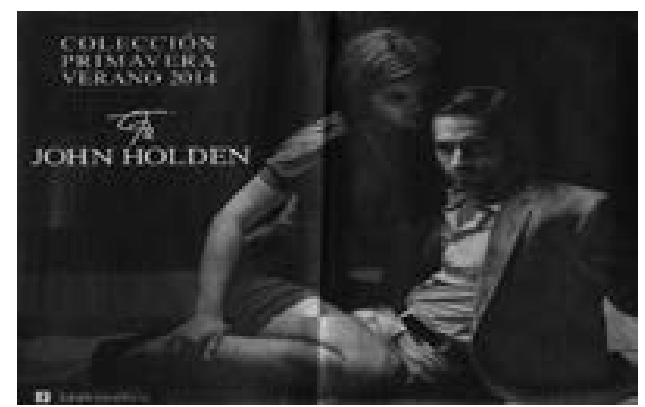

De este modo, la Junta Directiva del CONAR señaló lo siguiente:

"El numeral 1 establece que pueden ser considerados indecentes los anuncios en función de 'la naturaleza gráfica o explicita de las representaciones o descripciones de órganos o actividades sexuales o excretoras'. En la publicidad materia de denuncia se muestra la imagen de una mujer con vestido sentada sobre las piernas de un hombre que lleva una vestimenta casual. Si bien la imagen muestra a dos personas juntas y evoca una atracción de la modelo hacia el personaje que lleva puesta las prendas promocionadas, este órgano colegiado concuerda con la Comisión ${ }^{(10)}$ al considerar

c. Si el material parece explotar o excitar apetitos sexuales, o se presenta únicamente para llamar la atención del público por su impacto.

Al evaluar estos factores, principalmente el tercero, el contexto general de la transmisión será crítico. Cada caso puede presentar una combinación de estos, y quizás otros factores, los que tiene que ser evaluados equilibradamente para determinar si el material es abiertamente ofensivo y, por tanto, indecente. Usualmente un solo factor no basta para establecer la indecencia del material.

(9) De acuerdo a la doctrina y pronunciamientos de la entidad de autorregulación española, se establecen dos supuestos en los que una comunicación comercial puede resultar vejatoria para la mujer:

a) Utilización de forma particular y directa del cuerpo de la mujer o parte del mismo como mero objeto desvinculado del producto que se pretende promocionar, Para la mejor doctrina, la aplicación de esta regla requiere la concurrencia de tres supuestos: utilización del cuerpo femenino como parte captatoria de la publicidad, utilización del cuerpo como mero objeto, y desconexión total y absoluto entre la imagen utilizada y el producto promocionado.

b) Utilización de la imagen de la mujer asociada a comportamientos estereotipados coadyuvando a generar violencia de género. Serán ilícitos aquellos anuncios que, presentando a la mujer en el desempeño de actividades que tradicionalmente les han correspondido, transmitan el mensaje de que tales actividades son propias y exclusivas de las mujeres y que éstas vienen obligadas a asumirlas. Rubi i Puig, Publicidad y Libertad de Expresión, 88.

(10) En la página 11 de la Resolución No 1-2014-CONAR/CPE, la Comisión señaló expresamente lo siguiente "la Comisión cree que en la imagen descrita no se incorpora de manera gráfica o explícita, las representaciones o descripciones de órganos o actividades sexuales o excretoras". 
Autorregulación y la publicidad sexista: Oportunidad de mejora para el CONAR Self-regulation and sexist advertising: Opportunity for improvement for CONAR

que no se aprecia la representación gráfica o explicita de una actividad sexual.

(...)

En el anuncio materia de análisis los personajes no se muestran teniendo relaciones sexuales, o representando dichas actividades, pues solamente aparecen en una posición cercana que denota atracción. Asimismo, asumir que el consumidor percibirá que los personajes se encuentran inmersos en una relación sexual constituye un análisis forzado que no se condice con la interpretación natural e integral(11) que éste realiza de la publicidad, pues los modelos se encuentran completamente vestidos y de su sola cercanía no es posible inferir la representación de actividad sexual alguna.

(...)

La Junta Directiva considera importante resaltar que nos encontramos ante la evaluación de uno solo de los tres factores que orientan el análisis de la sexualidad y que el propio Código de Ética señala que usualmente ello no bastará para establecer la indecencia del material. En ese sentido, solo podrá determinarse la existencia de una infracción si con el análisis de ese solo factor el anuncio puede resultar abiertamente ofensivo.

(...)

Tomando en cuenta lo expuesto, este órgano colegiado considera que el anuncio denunciado no se orienta a explotar o excitar apetitos sexuales, ni muestran contenido sexual únicamente para llamar la atención del público por su impacto, pues las imágenes contenidas en el anuncio no se presentan de un modo que pueda ser considerado abiertamente ofensivo, conforme desarrollaremos a continuación.

En principio, cualquier manifestación de sensualidad o erotismo podría ser susceptible de explotar o excitar apetitos sexuales de alguno o varios receptores de los anuncios. No obstante, si tomáramos en cuenta únicamente ello para establecer la indecencia del material, la determinación de la infracción sería completamente arbitraria e implicaría una prohibición sobre cualquier uso de la sexualidad en la publicidad lo cual resulta contrario a lo establecido en nuestro Código de Ética Publicitaria.

En ese orden de ideas, la Junta Directiva considera que se podrá determinar la existencia de una infracción cuando se pueda apreciar que el anuncio efectivamente se orienta a explotar o excitar apetitos sexuales en los receptores. Ello puede presentarse, por mencionar algunos ejemplos, cuando el anunciante deliberadamente resalte evidente o insistentemente ciertas partes del cuerpo humano (mientras no sean órganos

(11) El artículo 3 del Código de Ética Publicitaria señala que los anuncios deben ser juzgados sobre la base de la interpretación natural e integral que el consumidor hace del mensaje publicitario. De acuerdo a lo indicado por este artículo, la interpretación integral abarca todo el contenido de un anuncio, incluyendo las palabras y los números hablados y escritos, los gestos y expresiones, las presentaciones visuales, musicales y efectos sonoros en una visión de conjunto. Esta norma precisa además que, al momento de evaluarse la publicidad, debe considerarse la diligencia del consumidor y las características específicas de los consumidores a quienes va dirigido el mensaje publicitario; concluyendo que, en el caso de la evaluación de una campaña publicitaria, la misma deberá ser analizada integralmente, comprendiendo la totalidad de los anuncios y los medios de comunicación que la conforman, así como la manera en que estos se complementan.

La interpretación natural a la cual hace referencia este artículo es aquella que surge a primera vista a los ojos del consumidor que observa el anuncio, sin tener que realizar interpretaciones alambicadas, complejas o forzadas del mismo. A fin de realizar esta interpretación, la Comisión deberá tener en cuenta el significado común que el consumidor le atribuiría a las palabras, frases, imágenes y demás elementos que integran el anuncio, considerando además la diligencia del consumidor al cual vaya dirigido el mensaje publicitario.

Por su parte, el análisis integral significa que la publicidad debe ser analizada en su conjunto, considerando la totalidad de elementos que conforman la misma en la medida que el consumidor, teniendo en cuenta no solo las palabras o frases utilizadas en la publicidad, sino también las imágenes y los demás elementos utilizados en el anuncio, siendo ésta es la forma en la cual un consumidor aprehende el mensaje publicitario. 
Alex Sosa

sexuales, pues en ese supuesto estaríamos frente a la infracción detallada en el numeral 1 del artículo 9) que podrían considerarse llamativas como el pecho, los glúteos o las piernas, o en el caso de actuaciones que se presenten evidentemente similares a una actividad sexual; sin embargo la indecencia de este contenido debe evaluarse en cada anuncio en concreto tomando en cuenta el producto o servicio promocionado.

Asimismo, este órgano colegiado concuerda con la Comisión respecto de que se debe evaluar la existencia de vinculación entre las imágenes contenidas y el producto o servicio que se está anunciando. Así, de acuerdo al análisis correspondiente, si un anuncio recurre a la sexualidad para publicitar productos que no tengan asociación alguna a su contenido, sería susceptible de vulnerar lo dispuesto por el Código de Ética, en la medida que podría estar usando la misma únicamente como objeto de impacto para captar la atención del público ${ }^{(12)}$. Sumado a ello, también se evaluará si el contenido de la publicidad erótica incorpora elementos que invoquen violencia sexual, incitación o reproducción de actos ilícitos, discriminatorios o el uso de imágenes eróticas que perjudiquen gravemente a la niñez o adolescencia(13).

Como este órgano ha tenido oportunidad de señalar en párrafos anteriores, el anuncio materia de análisis muestra a una mujer vestida, con una expresión que denota atracción, sentada sobre las piernas de un hombre que lleva una vestimenta casual de la marca promocionada.

Si bien la presente imagen evoca cierta sensualidad o erotismo moderado; no se encuentran elementos que nos permitan inferir que el anuncio se orienta efectivamente a excitar apetitos sexuales en los receptores, pues ambos personajes se presentan cubiertos por sus respectivas vestimentas limitándose a mostrar proximidad y atracción de uno hacía el otro, asociando el elemento de la seducción con sus prendas de vestir.

En efecto, este órgano colegiado considera perfectamente válido que un anunciante pretenda asociar marcas de prendas de vestir con imágenes que guardan cierto grado de seducción, pues resulta natural la idea de que una persona vestida de manera pulcra, creativa y/o elegante pueda generar atracción por parte de sus coetáneos. Así, de un análisis natural, integral y superficial del anuncio se puede apreciar que, mediante la imagen de una pareja en una situación provocativa, SAMITEX centra el discurso de su anuncio en que sus prendas de marca JH brindan elegancia, sofisticación y atracción por parte del sexo opuesto. Por lo tanto, la denunciada no presenta el contenido de su anuncio únicamente para llamar la atención del público por su impacto, sino que lo hace en estrecha relación con los atributos de su producto." (el énfasis es del autor)

En ese contexto de incertidumbre en el que el criterio se veía cuestionado por los propios pronunciamientos del CONAR, en ese mismo año decidimos (me incluyo porque soy coautor de aquel Código) modificar dichas restricciones y acercarlas más a lo que disponía el principio de adecuación social de la $\operatorname{LRCD}^{(14)}$, en tanto- como se indicó- la autorregulación tiene el deber de establecer principios compatibles con la norma que

(12) Relacionado con este criterio, recientemente la Oficina de Autocontrol en España analizó un caso en el cual se anunciaban productos agrícolas por medio de la imagen de una mujer y un montículo del producto promocionado, cerca de polvo del mismo, junto al siguiente texto: "Agricultor! Si quieres algo mejor que un polvo... pide un DISPERSS". En ese caso el Jurado entendió que la publicidad objeto de reclamación presenta a la imagen de la mujer como mero objeto desvinculado del producto que se pretende promocionar y junto a un eslogan de evidentes connotaciones sexuales (como "si quieres algo mejor que un polvo"). Resolución de 27 de marzo de 2014 del Asunto No 040/R/MARZO 2014. http://www.autocontrol.es/ pdfs/pdfs_resoluciones/rest1657.pdf. (consultada el 23 de abril de 2014)

(13) Un ejemplo de ello sería el uso de contenido pornográfico en publicidad externa (como paneles o vallas publicitarias). Generalmente en estos casos se prestará especial atención al medio de difusión de la publicidad.

(14) Código de Ética Publicitaria (2014) 


\section{Autorregulación y la publicidad sexista: Oportunidad de mejora para el CONAR Self-regulation and sexist advertising: Opportunity for improvement for CONAR}

regula la materia, y además, se buscaba reducir el nivel de discrecionalidad en la aplicación del código, cuando en realidad, ese riesgo solo es peligroso cuando el Estado aplica las normas, pues ello puede generar inseguridad jurídica por la falta de predictibilidad de sus pronunciamientos. Pero en el caso de los códigos deontológicos no sucede esto pues son códigos de conducta autoimpuestos y elaborados por especialistas de la propia industria publicitaria. Ellos mismos deciden sus límites -que no pueden ser menores que los que establece la LRCD- y pueden jugar con la discrecionalidad. $Y$ es que ese justamente es una de las grandes ventajas de la autorregulación publicitaria: a diferencia de los que elaboran normas para el Estado, los que elaboran sus códigos de conducta sí conocen cómo funciona la publicidad, los beneficios que genera a la sociedad y mercado, pero, sobre todo, cómo establecer límites o restricciones sin que ello implique la prohibición de determinado tipo de anuncios.

Lamentablemente, cuatro años después de la publicación de este Código, podemos verificar que no se presentó una sola denuncia más por anuncios de ese tipo, a pesar de que podemos coincidir que en estos últimos años sí se ha difundido publicidad sexista y que refuerza estereotipos negativos propios del machismo. ¿Qué pasó? ciertamente el efecto de este código fue negativo: Ios consumidores perdieron el único fuero viable con el que contaban para denunciar este tipo de anuncios a los mismos anunciantes (igual, actualmente, tienen uno tan bueno o mejor como las redes sociales).

De hecho, consideramos que, con la reforma del Código de Ética, el CONAR se alejó de una de las características principales de los sistemas de autorregulación: la represión de anuncios discriminatorios por género o contra la mujer. Un buen ejemplo de lo señalado es el código deontológico que aplica el sistema de autorregulación español, que señala en su artículo 10 lo siguiente: "la publicidad no sugerirá circunstancias de discriminación ya sea por razón de raza, nacionalidad, religión, sexo u orientación sexual, ni atentará contra la dignidad de la persona. En particular, se evitarán aquellos anuncios que puedan resultar vejatorios o discriminatorios para la mujer."

Sobre la aplicación de dicho artículo en el sistema de autorregulación español, Patiño sostiene que su aplicación puede ser objetiva: "al aplicar la norma deontológica 10, el Jurado solo dictó siete resoluciones estimatorias, frente a un total de veintiséis reclamaciones. En catorce de las campañas publicitarias examinadas, el objeto de la reclamación se fundamentaba en una discriminación por razón de sexo femenino. Es más: la mayoría de las reclamaciones se basaba en el desnudo femenino, que, según los reclamantes, demostraba la utilización de la mujer como un reclamo erótico. No obstante, el Jurado de la Publicidad sostuvo en varias resoluciones que en el siglo $X X I$ está socialmente admitido el uso moderado del desnudo humano o la provocación sugerente en publicidad, salvo que la presentación que se realice del mismo sea procaz o pornográfica. En este sentido, si se presenta el cuerpo humano de forma armónica y estética, no debería prohibirse su utilización publicitaria, puesto que tal sanción podría suponer una censura y un atentado contra la libertad de expresión (...). Según el Jurado, este derecho fundamental encuentra

Artículo 12.- Principio de Decencia y Sexualidad en la Publicidad

Los anuncios publicitarios deberán respetar la dignidad de las personas y su intimidad, el núcleo familiar, el interés social, las instituciones públicas y privadas, las autoridades legítimamente constituidas y los símbolos patrios.

En virtud de este principio, el mensaje publicitario no debe contener declaraciones o presentaciones visuales o de audio que ofendan, denigren o vulneren, entre otros, los derechos a la igualdad y a la no discriminación en razón de la raza, género, edad, religión, orientación sexual, nacionalidad, condición social, cultural o económica.

La publicidad no deberá inducir a los destinatarios del mensaje publicitario a cometer un acto ilegal o perjudicial para su seguridad personal o la de terceros.

El hecho que un producto o servicio en particular pueda ser considerado indecente para algunas personas no significa que ello será suficiente para objetar su validez, por lo que deberá ser revisado en cada caso en concreto. 
Alex Sosa

sus límites en los demás derechos constitucionalmente protegidos, tales como la dignidad de la persona. Sin embargo, si ésta se respeta, el simple desnudo de una mujer no debería ser discriminatorio". (15)

\section{3. ¿Qué debería hacer CONAR?}

Uno de los fundamentos de la existencia de la autorregulación es el demostrar al Estado que la industria publicitaria es lo suficientemente madura como para ocuparse de sus propios problemas y con ello reducir el riesgo de intervencionismo innecesario en la publicidad (muchas veces provocadas por el populismo político)(16).

Así, el ocuparse de la publicidad sexista podría ser una buena forma para que la industria publicitaria pueda demostrar madurez al Estado convirtiéndose en la vía idónea para que los consumidores puedan denunciar anuncios de este tipo, incentivando de este modo a sus miembros a comprometerse a hacer cada vez una mejor publicidad, sin discriminar o utilizar como un objeto a la mujer. Y lo mejor de todo: asumiendo las empresas privadas los costos de este compromiso, sin que ello realmente implique un gasto para el Estado(17)

Más allá de lo positivo que considero que ello podría ser para la industria publicitaria en general y los consumidores, es estratégicamente correcto que el CONAR se ocupe de fiscalizar este tipo de anuncios, pues de este modo se podría adelantar a la inminente regulación de esta figura, pues no debe faltar algún político oportunista que esté preparando el terreno para establecer prohibiciones en la publicidad. No olvidemos que una buena aplicación del Código de Ética en este terreno podría demostrar que la

(15) Beatriz Patiño, La Autorregulación Publicitaria. Especial referencia al sistema español, (Barcelona: Editorial Bosh, 2007), 292

(16) "Los críticos de la publicidad a menudo se oponen a la autorregulación precisamente porque está diseñada para anticiparse a futuras regulaciones. Su argumento es, en esencia, que la autorregulación en su forma moderna no es más que el sustituto débil e inferior de la regulación gubernamental. Esta visión es bastante errada. No existe la menor duda de que la regulación formal por lo general va muy lejos y por lo tanto victimiza a los consumidores. Afirmar que la autorregulación es menos intensa que la regulación gubernamental, es más un halago que una ofensa. Además, esta es un área donde privado implica tener grandes ventajas sobre la burocracia regulatoria”. Calfee, Miedo a la persuasión. Una nueva perspectiva de la publicidad y sus reglas, 116-117.

(17) Sobre la ética en los códigos de conducta de los sistemas de autorregulación David López ha señalado que "(...) la redacción de los documentos en los que se incluyen las normas de conducta resulta posible gracias al principio de la autonomía de la voluntad y, naturalmente, habrán de respetar la legislación tanto imperativa como semi-imperativa que, sobre el particular existe. Teniendo en cuenta tales condiciones, consideramos que los códigos de conducta deberán incluir las mejores prácticas publicitarias -y no meras herramientas de marketing corporativo- en el ámbito interactivo que, dicho sea de paso, tanto la propia industria como los destinatarios precisan.

En cuanto al contenido de las normas de conducta -recopiladas en un elevado número de supuestos, en los denominados códigos de conducta-, cabe decir que va más allá de la mera compilación de la normativa legal aplicable a la publicidad, pues incluyen consideraciones de índole ética. A este respecto, ciertos autores subrayan que la publicidad, por su propia naturaleza, tiene que ver con la conducta, con el ethos, y, por tanto, es susceptible de consideración ética.

En este último sentido, conviene efectuar un breve paréntesis e, inicialmente, precisar qué se entiende por ética, para posteriormente aplicar tal concepto a la publicidad. La ética representa un conjunto de principios o valores que gobiernan la conducta de una persona, grupo u organización, así como la convivencia en la sociedad. Ahora bien, como norma que juzga la conducta, no siempre coincide, de manera absoluta, en todos los supuestos, con las normas legales. Las leyes, en todo caso, marcan el umbral de la actuación ética.

La ética alude a las personas y no a las instituciones, por lo que su planteamiento, en el espacio publicitario, suele realizarse, con cierta frecuencia, desde una perspectiva relativista que prima la voluntad de la persona. No debe obviarse que depende de múltiples aspectos, como, entre otros, de los principios morales que el individuo acepte, el momento histórico y el ámbito cultural en el que se plantee. 


\section{Autorregulación y la publicidad sexista: Oportunidad de mejora para el CONAR Self-regulation and sexist advertising: Opportunity for improvement for CONAR}

autorregulación publicitaria es una alternativa menos costosa a la regulación estatal.

CONAR ya demostró en el mercado que no tiene nada que envidiarle al INDECOPI en nivel de tecnicismo, pero aún le falta demostrar a la industria publicitaria y a la sociedad que puede ocuparse de reprimir anuncios que refuercen estereotipos negativos y hagan uso de la publicidad sexista como herramienta de competencia, toda vez que estos son los que terminan desprestigiando la actividad publicitaria de los anunciantes que sí quieren hacer las cosas bien.

\section{Referencias bibliográficas}

Calfee, John. 2013. Miedo a la persuasión. Una nueva perspectiva de la publicidad y sus reglas. Lima: Themis.
Fletcher, Winston. 2010. Advertising. A Very Short Introduction. New York: Oxford University Press.

García, Javier. 2016. Dispublicitados. Los efectos (ideológicos) de la publicidad. Murcia: Universidad de Murcia.

Lema, Carlos. 2007. Problemas Jurídicos de la Publicidad. Madrid: Marcial Pons, Ediciones Jurídicas y Sociales.

López, David. 2013. La publicidad en Internet. Regulación y autorregulación. Pamplona: Editorial Aranzadi.

Patiño, Beatriz. 2007. La Autorregulación Publicitaria. Especial referencia al sistema español. Barcelona: Editorial Bosh.

Posner, Richard. 1998. El análisis económico del Derecho. México: Fondo de Cultura Económica.

Rubi i Puig, Antoni. 2008. Publicidad y Libertad de Expresión. Pamplona: Editorial Aranzadi.

\section{$(\ldots)$}

Representa, asimismo, un valor -la ética- que engendra confianza en las relaciones comerciales, por lo que, en consecuencia, las favorece. Por ello, desde la perspectiva de la eficiencia del mercado, la actuación comercial de la empresa debe estar orientada al bien común, entendiendo por tal aquel que represente un desarrollo humano integral, no solo económico, Aunque puede ser una obviedad, para que estos comportamientos sean éticos deben serlo también las acciones generales de la sociedad.

Tras todo lo apuntado, podríamos definir la publicidad ética como aquella comunicación cuya recepción no vulnere el conjunto de valores sociales, culturales religiosos y morales del grupo social que resulte afectado por el mensaje, dando lugar a una merma del bienestar común. Aunque, en la práctica, lo más frecuente será que la publicidad ética coincida con la publicidad lícita, no será óbice para que el contenido de un mensaje comercial, calificado normativamente como lícito, vulnere el conjunto de valores sociales que comentamos, suscitando, de esta forma, cierto malestar. Es más, en la práctica, existen actuaciones vinculadas con la publicidad -lo cual es especialmente visible en la difundida en la red- que pueden no estar reguladas por la ley que pueden reputarse no éticas". David López Jiménez, La publicidad en Internet. Regulación y autorregulación, (Pamplona: Editorial Aranzadi, 2013), 59-63 